\title{
Evapotranspiration Partitioning and Response to Abnormally Low Water Levels in a Floodplain Wetland in China
}

\author{
Xiaosong Zhao and Yuanbo Liu \\ Key Laboratory of Watershed Geographic Sciences, Nanjing Institute of Geography and Limnology, \\ Chinese Academy of Sciences, Nanjing 210008, China \\ Correspondence should be addressed to Yuanbo Liu; ybliu@niglas.ac.cn
}

Received 23 October 2015; Revised 18 February 2016; Accepted 27 March 2016

Academic Editor: Nir Y. Krakauer

Copyright (c) 2016 X. Zhao and Y. Liu. This is an open access article distributed under the Creative Commons Attribution License, which permits unrestricted use, distribution, and reproduction in any medium, provided the original work is properly cited.

Evapotranspiration (ET) is an important component of the wetland water budget. Water level declines in Poyang Lake, the largest freshwater lake in China, have caused concerns, especially during low water levels. However, how wetland ET and its partitioning respond to abnormally low water levels is unclear. In this study, wetland ET was estimated with MODIS data and meteorological data. The wetland ET partitioning and its relationship with abnormally low water levels were analyzed for 2000-2013. The results showed that the water evaporation rate $\left(E_{\text {water }}\right)$ was larger than the land $\mathrm{ET}$ rate $\left(\mathrm{ET}_{\text {land }}\right)$; the $\mathrm{ET}_{\text {land }} / E_{\text {water }}$ ranged from 0.77 to 0.99 . When the water level was below $12.8 \mathrm{~m}$, the ET partition ratio was larger than 1 , which indicates that wetland ET comes from land surface ET more than water evaporation. The negative standardized water level index (SWI) was used to represent an abnormally low water level in the wetland. Although the monthly wetland ET decreased as the negative SWI decreased, $\mathrm{ET}_{\text {land }}$ was higher than the average under negative SWI conditions from September to December, when the water level decreased. The abnormally low water level induced more water loss from the land surface, especially when the water level decreased, which reduced the available water resources along the wetland shore.

\section{Introduction}

Evapotranspiration (ET) is the major factor that controls water balance in nearly all wetlands. Floodplain wetlands are hydrologically complex components of the landscape and are located at the transition between aquatic and terrestrial ecosystems $[1,2]$. Water vapor fluxes, especially evapotranspiration, can be highly variable because of intermittent flooding and a diversity of plant communities, which may differ in their water use characteristics and responses to water level changes.

Changes in the proportion of water lost via ET from land surfaces versus evaporation $(E)$ from water bodies relative to the total wetland ET affect ecological, biogeochemical, and hydrological cycles at multiple temporal and spatial scales in floodplain wetlands [3]. Many studies have highlighted the linkage between ET partitioning versus water level and vegetation cover in wetlands [4-8]. Changes in water levels for shallow lakes can transform an aquatic environment into an exposed environment, or vice versa. Land surface covers are typically reflected in the shifting dynamics, productivity, and spatial distribution of wetland communities $[7,9,10]$. Vegetation cover and soil conditions are also important factors that affect the rate of water loss [11]. Booth and Loheide [5] showed that changes in ET partitioning occurred because of changes in Leaf Area Index (LAI), plant water stress function, and available storage in the upper soil layer. Decreasing the LAI increased the partitioning of ET toward evaporation. Sánchez-Carrillo et al. [7] indicated that increased vegetation cover did not significantly reduce evapotranspiration but did increase the transpiration to evaporation ratio and the open water area, which increased the wetland evapotranspiration. Huxman et al. [12] identified the partitioning of ET as one of the most important ecohydrological challenges in understanding vegetation dynamics and succession in floodplain wetlands.

Poyang Lake is the largest freshwater lake in China [13, 14]. It is a typical floodplain wetland with dramatic seasonal 
water level variations that cause inundation areas to vary remarkably from several thousand square kilometers during the summer to less than one thousand square kilometers during the winter [15-17]. Poyang Lake wetland is well known and was listed on the Ramsar Convention List of Wetlands of International Importance (the Ramsar Convention 2012) to protect migration bird species and habitats for rare and endangered species [18-20]. Unfortunately, the water level and inundation area in Poyang Lake wetland have significantly decreased; moreover, the duration of extreme low water events has increased in the previous decade $[13,15,21]$. These changes have affected the water supply, water quality, wetland, and aquatic habitats [22].

The above problems have caused great concern for researchers. Some studies have focused on investigating recent low water levels and explaining their causes [13-15, 23]. Liu et al. [13] revealed a regime shift in the lake size that began in 2006; the trigger for the recent lake level declines was principally attributed to low water levels in the Yangtze River and enhanced outflows from Poyang Lake. Zhang et al. [24] related the low water level to the effect of local catchment and lake-river interactions. Lai et al. [23] indicated that increasing the discharge ability of Poyang Lake into the Yangtze River at low water levels enhanced the drought risk in Poyang Lake. Other studies have examined the effect of recent water level declines on vegetation dynamics and hydrological processes in Poyang Lake wetland [25-28]. Zhang et al. [26] analyzed the relationship between hydrological conditions and the distribution of vegetation communities, whereas $\mathrm{Yu}$ et al. [28] indicated that recent low water levels have accelerated positive succession in wetland vegetation. Zhao and Liu [27] examined the impact of water level fluctuations on wetland ET, which indicated that the annual ET decreased because of falling water levels. The effect of water level changes on vegetation and hydrological processes has been attributed to water allocation and hydrological gradients in the wetland. Water vapor loss along the shore of Poyang Lake wetland was the primary component of ET when the water level decreased, which affected the water budget and vegetation growth [27]. Some studies have indicated that the long-term exposure of the wetland shore promoted vegetation growth from September to December, during which the water level decreased [25]; this high biomass may increase the land surface ET. However, the long-term exposure of the land surface also causes soil water deficits [7], which typically decrease the land surface ET. How the wetland ET and its partitioning in Poyang Lake wetland respond to abnormally low water levels in different seasons remains unclear.

A better understanding of the response of wetland ET partitioning is essential for the rational utilization of water resources and wetland ecosystem protection. This study estimated wetland ET based on remote sensing data and meteorological data. The objectives were to (1) identify abnormally low water levels over the previous decade, (2) analyze variations in wetland ET and its partitioning, and (3) explore the relationship between ET partitioning and abnormally low water levels.

\section{Study Area}

Poyang Lake is located in the middle of the Yangtze River Basin $\left(28.2^{\circ}-30.0^{\circ} \mathrm{N}\right.$ and $115.5^{\circ}-116.5^{\circ} \mathrm{E}$ ) (Figure 1). Poyang Lake wetland has a subtropical monsoon climate. The annual mean temperature is $17.1^{\circ} \mathrm{C}$, and the annual precipitation is $1620 \mathrm{~mm}$ (1958-2013), of which 55\% occurs from March to June. Poyang Lake receives inflows from five major rivers (i.e., Xiushui, Ganjiang, Fuhe, Xinjiang, and Raohe) within the basin and discharges into the Yangtze River. The dominant land covers include forest, agricultural fields, grasslands, bare lands, and water surfaces.

Under the Ramsar wetland conservation treaty, Poyang Lake belongs to a wetland type of seasonal or intermittent freshwater lake under inland wetland classifications. Figure 1 shows Poyang Lake wetland with the minimum inundated area. The water levels were measured at Xingzi using the Wusong reference elevation system. Poyang Lake undergoes very large seasonal water level variations, which alters the lake's inundation area. During the flood season (from April to September), these five contributing tributaries are flooded because of concentrated rainfall, which results in a maximum lake surface area of over $3000 \mathrm{~km}^{2}$ [29]. During the dry season (from October to March), the surface area of the lake shrinks to less than $1000 \mathrm{~km}^{2}[13,15]$.

\section{Methods and Data Source}

3.1. Method Overview. Poyang Lake wetland includes water and land surfaces, which have different evaporation or ET processes. Evaporation from the water surface $\left(E_{\text {water }}\right)$ and ET from the land surface $\left(\mathrm{ET}_{\text {land }}\right)$ were both estimated in this study. The wetland ET is partitioned into water surface evaporation and land surface ET using the water surface area percentage $(A)$ in Poyang Lake wetland. The wetland ET was estimated using

$$
\begin{aligned}
\mathrm{ET}_{\text {wetland }} & =C_{E_{-} \text {water }}+C_{\mathrm{ET}_{\text {_land }}} \\
& =E_{\text {water }} \cdot A+\mathrm{ET}_{\text {land }} \cdot(1-A),
\end{aligned}
$$

where $\mathrm{ET}_{\text {wetland }}$ is the spatially averaged wetland ET rate, which is separated into a water surface evaporation component $\left(C_{E_{-} \text {water }}\right)$ and a land surface ET component $\left(C_{\mathrm{ET} \text { land }}\right)$. Moreover, $C_{E_{-} \text {water }}$ is the water evaporation rate $\left(E_{\text {water }}\right.$, $\mathrm{mm} /$ day $/ \mathrm{m}^{2}$ ) multiplied by the water surface area proportion $(A, \%)$, and $C_{\mathrm{ET} \text { land }}$ is the land surface rate $\left(\mathrm{ET}_{\text {land }}\right.$, $\mathrm{mm} /$ day $/ \mathrm{m}^{2}$ ) multiplied by the land surface area proportion $(1-A, \%)$. To analyze wetland ET partition, the ET partition ratio is defined as the ratio of $C_{\mathrm{ET} \text { land }}$ to $C_{E_{-} \text {water }}$ :

$$
\text { ET partition ratio }=\frac{\mathrm{ET}_{\text {land }} \cdot(1-A)}{\left(E_{\text {water }} \cdot A\right)} .
$$

Based on the Priestley-Taylor equation, ET can be expressed as follows:

$$
\mathrm{ET}=\Phi\left(\frac{\Delta}{\Delta+\gamma}\right)\left(R_{n}-G\right),
$$

where ET is evapotranspiration or evaporation $\left(\mathrm{W} \mathrm{m}^{-2}\right)$, $\Phi$ is the Priestley-Taylor parameter, $R_{n}$ is the net 


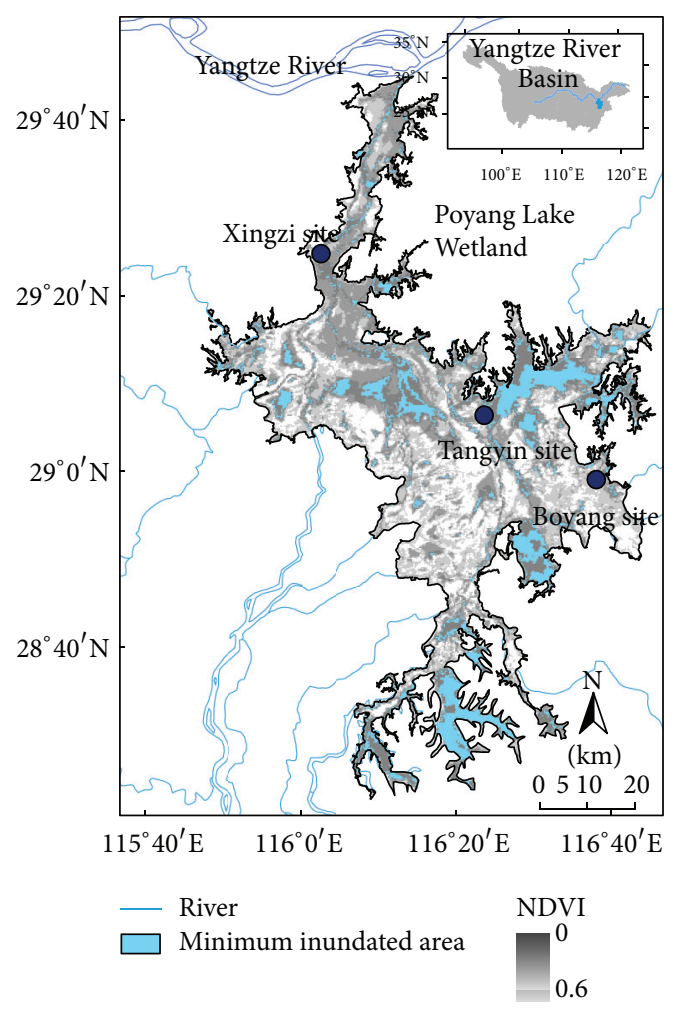

FIgURE 1: Geographic location of Poyang Lake wetland with minimum water surface areas in 2006.

radiation $\left(\mathrm{W} \mathrm{m}^{-2}\right), G$ is the soil heat flux $\left(\mathrm{W} \mathrm{m}^{-2}\right), \Delta$ is the slope of the saturation vapor pressure at the air temperature $\left(T_{a}\right)$, and $\gamma$ is the psychrometric constant $\left(\mathrm{hPa} \mathrm{K}^{-1}\right)$.

The land surface ET was estimated by the $T_{s}$-VI triangle method [30] from MODIS data. The modified PriestleyTaylor equation was used on meteorological data to estimate water body evaporation. The lake surface area percentage was extracted by the normalized difference water index (NDWI) from MODIS data. The details of these methods are described as follows.

3.2. Evapotranspiration Estimation for the Land Surface by the Triangle Method. In this study, the $T_{s}$-VI triangle method [30] was applied to estimate ET over Poyang Lake wetland. The advantages of the $T_{s}-\mathrm{VI}$ triangle method for ET estimation are that (1) the complex parameterization of aerodynamic resistance and uncertainty from the replacement of aerodynamic temperature is bypassed, (2) no groundbased near-surface measurements are required, and (3) the ET estimation is independent of land-cover types [31]. The Priestley-Taylor parameter, which was proposed by Jiang and Islam [32] and is based on the Priestley-Taylor equation and the existence of a physically meaningful relationship between remotely sensed surface temperatures and the vegetation index, is expressed as in the following equation:

$$
\Phi=\Phi_{\max } \frac{T_{\max }-T_{s}}{T_{\max }-T_{\min }}
$$

where $\Phi_{\max }$ is the Priestly-Taylor coefficient of 1.26 [33]. $T_{s}$ is the land surface temperature $(\mathrm{K}) . T_{\min }$ is the lowest temperature in the full vegetation cover, which forms the wet edge in the triangle space of $T_{s}$ versus NDVI. $T_{\max }$ is the highest temperature at a given NDVI and can be obtained by extrapolating the dry edge to intersect with NDVI $=0$. The two boundaries of the $T_{s} / \mathrm{NDVI}$ feature space constitute limiting conditions for the surface fluxes. Three steps are thus required to estimate $\Phi$ as follows: (1) establish the boundaries of the triangle, (2) interpolate $\Phi$ along the dry edge, and (3) linearly interpolate between the highest and lowest $T_{s}$ for a given value of NDVI. Then, the wet and dry edges of the triangular space are determined by using the algorithm that was described by Tang et al. [31]. Finally, the $\Phi$ value for each pixel in the study area is calculated from the triangular space.

The net radiation $\left(R_{n}\right)$ is the sum of the shortwave net radiation and longwave net radiation. The algorithm that was proposed by Bisht et al. [34] was applied to estimate the daily $R_{n}$ entirely from MODIS products. Then, the daily ET was estimated from the daily net radiation and near-noon instantaneous evaporative flux (EF) ratio. EF was defined as the ratio of ET to available energy $\left(R_{n}-G\right)$ [35]. Missing ET values in the time series from cloud cover in satellite images were reconstructed based on the potential ET (based on the Penman-Monteith equation [31]) and the estimated ET on a clear day [36]. Additional detailed information about soil heat flux estimation and daily ET estimation is available in Zhao and Liu [27]. The calibration and validation of ET estimation in Poyang Lake wetland were also shown in Zhao and Liu [27]. The estimated land surface ET by the triangle method showed good agreement with the observed ET by Lysimeter in Poyang Lake wetland, that is, a regression slope of 0.97 and a correlation coefficient $\left(R^{2}\right)$ of 0.49 . At the annual scale, the relative error of the estimated ET was 5.4\%, which suggests a satisfactory accuracy.

\subsection{Evaporation Estimation for Water Bodies by the Modified} Priestley-Taylor Equation. The Priestley-Taylor (P-T) coefficient, which is based on the Priestley-Taylor equation (2), was assumed to be constant (i.e., 1.26) for water evaporation estimation studies [37-39]. However, research has shown that the $\mathrm{P}-\mathrm{T}$ coefficient for evaporation over an open water body is not constant because of its association with ambient atmospheric vapor pressure deficits [40]. In this study, the modified Priestley-Taylor equation was developed to estimate water body evaporation through revising the P-T coefficient equation. According to bulk aerodynamic methods and the evaporation observations [41, 42], the P-T coefficient can be calculated as a function of the wind velocity and vapor pressure deficit as follows:

$$
\Phi=f(U, \mathrm{VPD}),
$$

where $U$ is the wind velocity at a height of $2 \mathrm{~m}_{\left(\mathrm{m} \mathrm{s}^{-1}\right) \text { and }}$ VPD is the saturation vapor pressure deficit $(\mathrm{kPa})$, which is equivalent to $e_{s}-e_{a}$, where $e_{s}$ is the saturation vapor pressure at a given air temperature and $e_{a}$ is the actual vapor pressure. These parameters can be obtained via in situ meteorological measurements. Compared with land surfaces, the latent heat 
flux from water surfaces has a high proportion of net radiation because of the large heat capacity of water. The heat flux that is transferred in water was determined from profile measurements of the water temperature [43]. The meteorological parameters for estimating the water evaporation in this study were obtained from in situ measurements.

3.4. Water Surface Area Extraction. The lake's surface area was extracted by using the normalized difference water index (NDWI) [44]. The NDWI can be expressed as follows:

$$
\mathrm{NDWI}=\frac{(\text { Green }-\mathrm{NIR})}{(\text { Green }+ \text { NIR })},
$$

where NIR is the surface reflectance in the NIR band and Green is the reflectance in the green band. The MODIS product MOD09 provides surface reflectance in the green and NIR bands. The water surface area was delineated by using a thresholding segmentation algorithm that was based on the NDWI $[45,46]$. The regression function for the water surface area proportion $(A)$ and water level $(W)$ at the Xingzi station was found to be $A=-0.056 \times W^{3}+2.29 \times W^{2}-23.66 \times$ $W+88.48\left(R^{2}=0.91\right)$. Based on this function, the daily lake surface area percentage could be calculated for 2000 to 2013.

3.5. Water Level Index. The standardized water level index (SWI) was used to quantify the magnitude of water level deviations from the mean value over multiple time scales. McKee et al. [47] defined the SWI as follows:

$$
\mathrm{SWI}_{i j}=\frac{\left(W_{i j}-\overline{W_{j}}\right)}{\sigma_{j}},
$$

where $W_{i j}$ is the normalized monthly water level of year $i$ and month $j(j=1,2, \ldots, 12), \overline{W_{j}}$ is the multiyear mean of monthly water level for month $j$, and $\sigma_{j}$ is the standard deviation of monthly water level for month $j$. Negative SWI values represent below-average water levels, whereas positive values represent above-average water levels. The magnitude of the SWI indicates the extent of the water level anomaly from the average.

3.6. Remote Sensing Data. The Terra-MODIS Collection 5 data products that were used in this study included MODIS geolocation (MOD03), the atmospheric profile product (MOD07), the surface reflectance (MOD09), the land surface temperature/emissivity product (MOD11_L2), and the albedo product (MOD43). MOD03 contains solar zenith and azimuth angles and satellite zenith and azimuth angles. MOD07 provides air temperatures and dew point temperatures. MOD09 provides surface reflectance in seven reflective bands and includes values that were corrected for radiometric and atmospheric effects. MOD11_L2 contributes $1 \mathrm{~km}$ land surface temperatures and surface emissivity in bands 31 and 32. The MOD43B3 product provides clear-sky observations at $1 \mathrm{~km}$ spatial resolution and albedo. To satisfy the spatial resolution and maximize the remote sensing information, all the parameters from the MODIS products were resampled to a $250 \mathrm{~m}$ resolution by using a nearest-neighbor algorithm.
Because of weather and cloud cover, remote sensing images were limited to available data in the visible band, nearinfrared band, and thermal infrared band. Based on cloud detection, images with less than $15 \%$ clouds were selected to estimate the regional ET. Many of the 469 images satisfied the above condition in Poyang Lake Basin for 2000-2013. Pixel gaps in the images from cloud cover were gap-filled by using the nearest-neighbor method.

3.7. Evaporation and Meteorological Data. Water evaporation was measured with an E-601 evaporation pan at the Tangyin station (Figure 1). The P-T coefficient in (4) was determined and calibrated based on the evaporation measurements from 2000 to 2012. The pan evaporation data in 2013 were used to validate the estimated evaporation. Meteorological data, including the daily air temperature, relative humidity, solar radiation, precipitation, and $2 \mathrm{~m}$ wind speed measurements, from Boyang $\left(29.0^{\circ} \mathrm{N}\right.$ and $\left.116.7^{\circ} \mathrm{E}\right)$ station are available from the China Meteorological Data Sharing Service System at http://data.cma.cn/ for 1958-2013. Water level data from Xiangzi station were obtained from the Hydrological Bureau of the Yangtze River Water Resources Commission for 19602013.

Based on meteorological stations around Poyang Lake, the coefficients of variation (CV) (CV $=\mathrm{SD} /$ Mean $* 100 \%$; SD is standard deviation) of air temperature, relative humidity, and wind speed were calculated, which were $6 \%, 7 \%$, and $25 \%$, respectively. The spatial variability of net radiation in Poyang Lake was neglected due to mixing well in water body. According to sensitivity analysis of the modified PriestleyTaylor equation, the net radiation, air temperature, wind speed, and relative humidity can explain the evaporation variation of $58 \%, 18 \%, 13 \%$, and $11 \%$, respectively. In conclusion, the effect of spatial variability of meteorological parameters on evaporation estimation was less than $3 \%$.

\section{Results}

4.1. Validation. Good agreement exists between the estimated evaporation and the pan evaporation in monthly scale over Poyang Lake ( $R^{2}$ of 0.67 and RMSE of $18.7 \mathrm{~mm} \mathrm{month}^{-1}$; Figure 2). Though evaporation that was estimated by the modified Priestley-Taylor equation was lower than the measurements at high value, which is an obviously improved estimation accuracy compared with the evaporation from the Priestley-Taylor equation, $\Phi=1.26$ ( $R^{2}$ of 0.23 and RMSE of $31.4 \mathrm{~mm} \mathrm{~d}^{-1}$ ).

4.2. Monthly Variation in Water Level Changes and SWI. Clear seasonal and interannual variations occur with monthly precipitation from Poyang Lake catchment and the water level at Xingzi site for 2000-2013 (Figure 3(a)). Based on seasonal variations in the water level, Poyang Lake wetland can be divided into four distinct periods as follows: a dry season (low water level from January to March), a rising period (increasing water level from April to June), a flood season (high water level from July to September), and a retreating period (decreasing water level from October to December) [48]. Notably, the monthly water level variation 


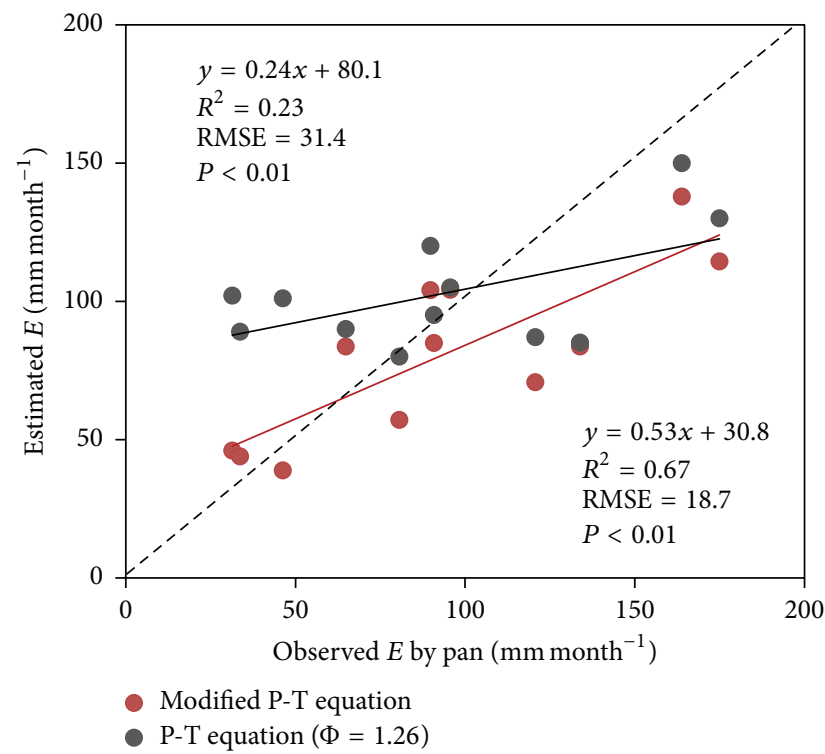

FIGURE 2: Validation of the estimated water evaporation based on pan evaporation that was conducted at the Tangyin site in 2013.

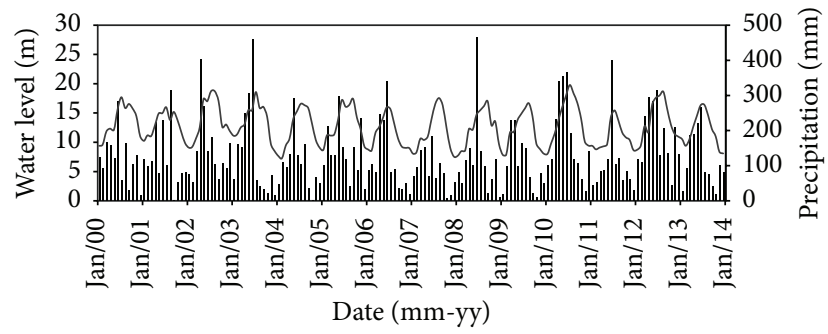

(a)

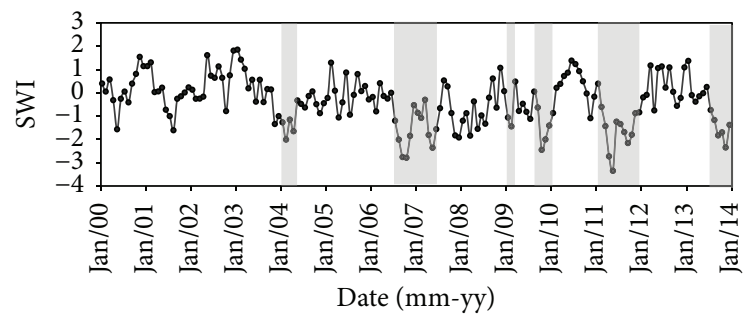

(b)

FIGURE 3: Monthly time series of (a) the water level and precipitation and (b) the standardized water level index (SWI). The gray areas indicate negative SWI values during typical drought years (i.e., 2004, 2006, 2007, 2009, 2011, and 2013).

was not completely consistent with the observed precipitation. Precipitation was concentrated from March to June, decreasing rapidly thereafter; however, the water level remained high from July to September because of the high water level in Yangtze River and blocked outflows from Poyang Lake [14, 29].
The standardized water level index (SWI) indicates the extent that the water level is above or below average (Figure 3(b)). Abnormally low water levels are identified (negative SWI values) for 42 months (13 months during the retreating period, 12 months during the flood season, 10 months during the rising period, and 7 months during the dry season). The maximum negative SWI was -3.35 , which occurred in May 2011. When considering both the duration and magnitude of the negative SWI conditions, typical drought years were confirmed in 2004 (from January to April, lasting 4 months), 2006 (from July to December, lasting 6 months), 2007 (January to June, lasting 6 months), 2009 (January to February and November to December, 4 months), 2011 (February to October, lasting 9 months), and 2013 (August to December, lasting 5 months).

4.3. Variation in Wetland ET and Its Partitioning. Poyang Lake wetland lost water from both evaporation from the water surface $\left(E_{\text {water }}\right)$ and ET from the land surface $\left(\mathrm{ET}_{\text {land }}\right)$. Seasonal variations in $\mathrm{ET}_{\text {land }}$ and $E_{\text {water }}$ had a single peak (Figure 4(a)); the maximum ET typically occurred in July, and the minimum occurred in January. The monthly $E_{\text {water }}$ ranged between $33.9 \mathrm{~mm}$ and $183.9 \mathrm{~mm}$ from 2000 to 2013, which was higher than the $\mathrm{ET}_{\text {land }}(33.0 \mathrm{~mm}$ to $154.9 \mathrm{~mm}$ ). The $\mathrm{ET}_{\text {land }} / E_{\text {water }}$ was lower during the summer and higher during the winter (Figure 4(b)), ranging from 0.77 to 0.99 (average of 0.87).

The ET partition ratio indicates the partitioning of $\mathrm{ET}_{\text {wetland }}$ into water surface $E$ and land surface ET over Poyang Lake wetland. When the ET partition ratio is larger than 1, more wetland ET came from the land surface. The average monthly ET partition ratio ranged from 0.11 to 4.8 ; the ratio was less than 1 from May to September and exceeded 1 in the other months (Figure 5(a)). The ET partition ratio during the dry season was larger than that during the retreating season. The annual mean ET partition ratio ranged from 0.53 to 1.55 (Figure 5(b)); the high ratio values occurred in $2004,2006,2007,2009,2011$, and 2013, corresponding to the drought years in the wetland (as indicated by the SWI values). In those years, the ET partition ratio in the months with abnormally low water levels was substantially above average. Drought years were divided into three categories based on the time of year that a negative monthly SWI value occurred as follows: (1) the dry and rising seasons (January to May), that is, in 2004 and 2007 (Figure 6(a)); (2) the flood and retreating seasons (September to December), that is, in 2006 and 2013 (Figure 6(b)); and (3) the dry and retreating seasons, that is, in 2009 and 2011 (Figure 6(c)). The magnitude and length of time of the high ratio values indicate the intensity and duration of the abnormally low water levels over Poyang Lake wetland.

4.4. Response in Wetland ET to Abnormally Low Water Levels. The magnitude, timing, and duration of low water levels affect wetland ET and its partitioning. The $\mathrm{ET}_{\text {land }} / E_{\text {water }}$ reflects the effect of land surface changes that are caused by water level changes. The $\mathrm{ET}_{\text {land }} / E_{\text {water }}$ was not correlated with the water level during the study period (Figure $7(\mathrm{a})$ ). The data were scattered from 0.77 to 0.99 when the water level 


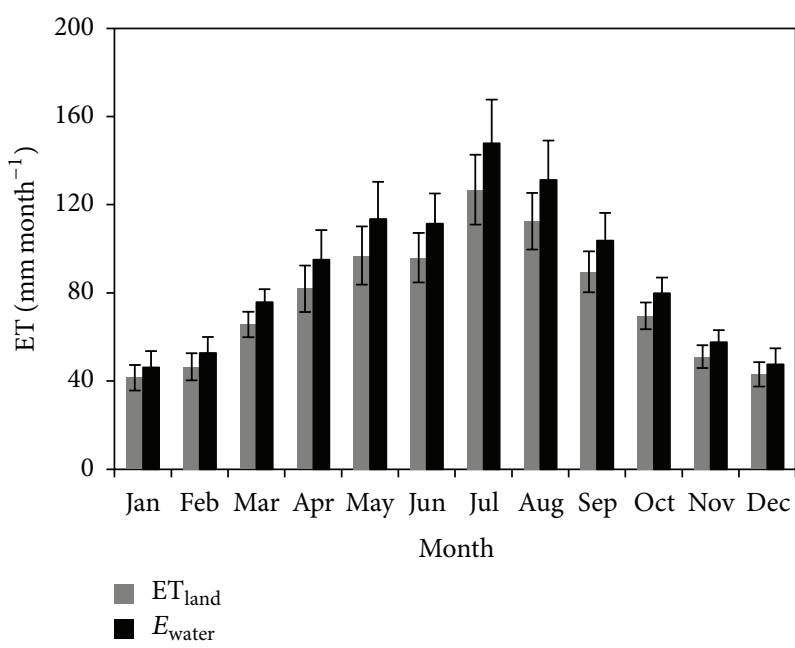

(a)

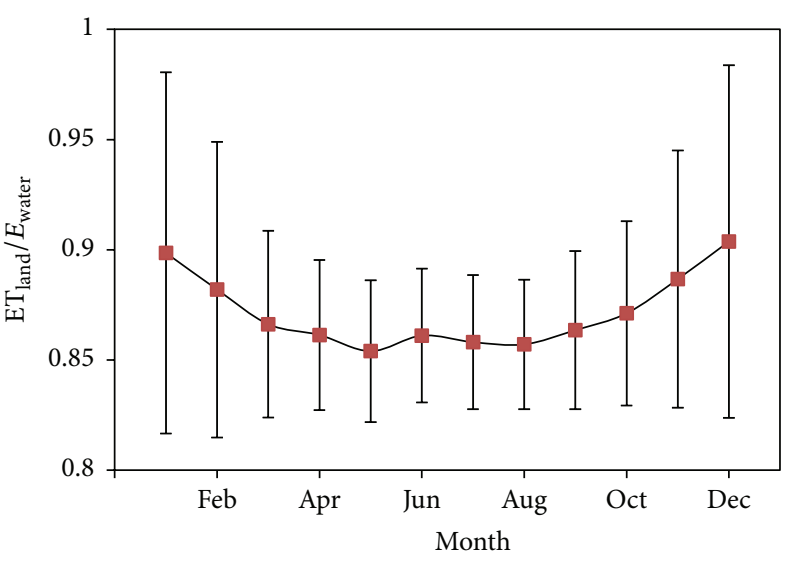

(b)

FIGURE 4: Monthly variations in (a) the mean land surface ET $\left(\mathrm{ET}_{\text {land }}\right)$ and water evaporation $\left(E_{\text {water }}\right)$ and $(\mathrm{b})$ the $\mathrm{ET}_{\text {land }} / E_{\text {water }}$ averaged from 2000 to 2013. The error bars refer to \pm 1 SD of the average.

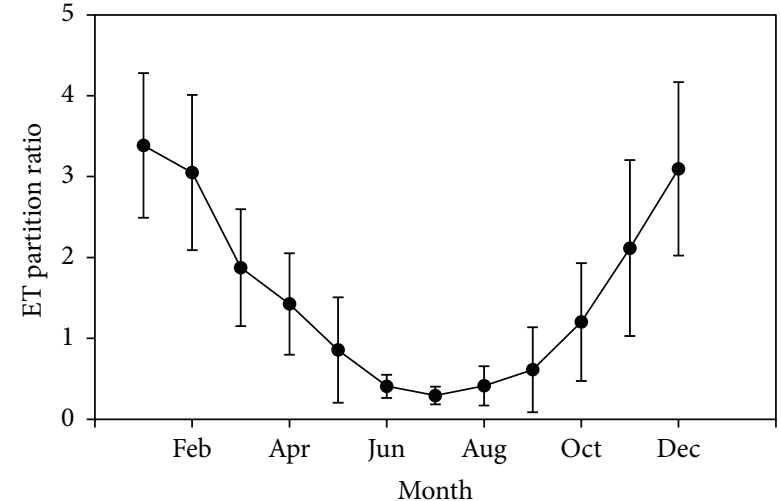

(a)

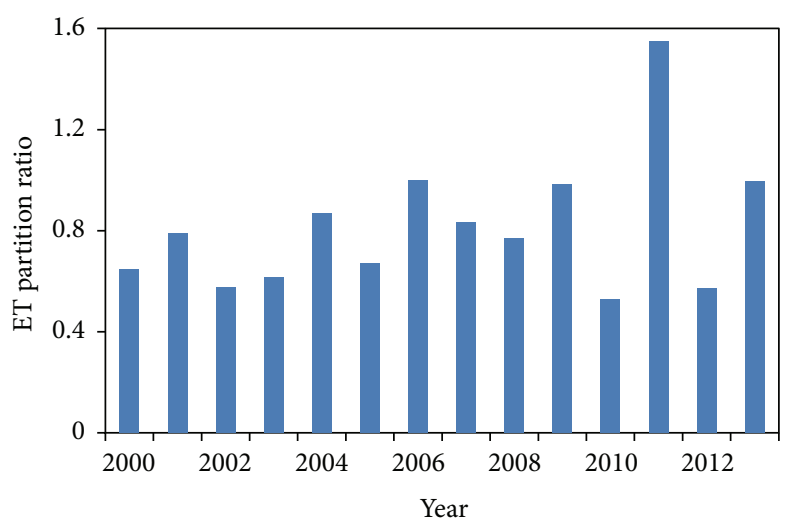

(b)

FIgURE 5: (a) Monthly and (b) annual variations in the ET partition ratio from 2000 to 2013; the error bars refer to \pm 1 SD of the average.

was below $12 \mathrm{~m}$, whereas the $\mathrm{ET}_{\text {land }} / E_{\text {water }}$ tended to be constant (0.9) when the water level exceeded $12 \mathrm{~m}$. The same phenomenon was observed in the relationship between the $\mathrm{ET}_{\text {land }} / E_{\text {water }}$ and the SWI (Figure $7(\mathrm{~b})$ ). Notably, the $\mathrm{ET}_{\text {land }} / E_{\text {water }}$ during the retreating season was always larger than those during the dry and rising seasons during drought years under low water levels and negative SWI values. The response of the land surface ET and wetland ET anomaly with respect to SWI during typical drought months indicates that the land surface ET anomaly was primarily greater than 0 during the retreating season (September to December; Figure 8) and exhibited a negative SWI, whereas the opposite occurred during the dry and rising seasons (January to May) (Figure 8(a)). The anomaly in the wetland ET increased with increasing SWI during the retreating, dry, and rising seasons (Figure 8(b)), which indicates that the more severe the drought, the lower the wetland ET compared with the average.

\section{Discussion}

The ET in Poyang Lake wetland was separated into evaporation from the water body and ET from the land surface. The annual ET partition ratio ranged from 0.57 to 1.55 and the low water level corresponded to a high ET partition ratio. This relationship has also been observed in other wetlands [7]. For a semiarid wetland in central Spain, evaporation from open water exhibited twice the evapotranspiration rate during high water level periods [7]. As a result, a lower water level (more land surface exposed) can increase the land surface ET's contribution to the wetland ET and decrease the wetland ET.

During drought years, the land surface ET ( $\left.\mathrm{ET}_{\text {land }}\right)$ increased during the retreating season and decreased during the dry and rising seasons over Poyang Lake wetland. The land surface ET includes evaporation from soil and transpiration from vegetation. Abnormally low water levels occurred during the retreating seasons during 2006, 2009, 2011, and 


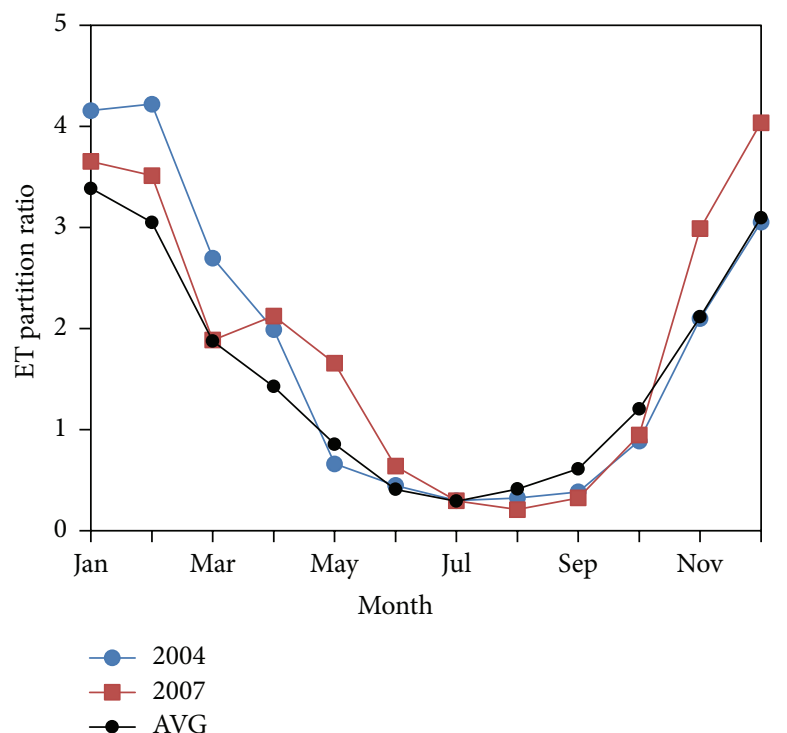

(a)

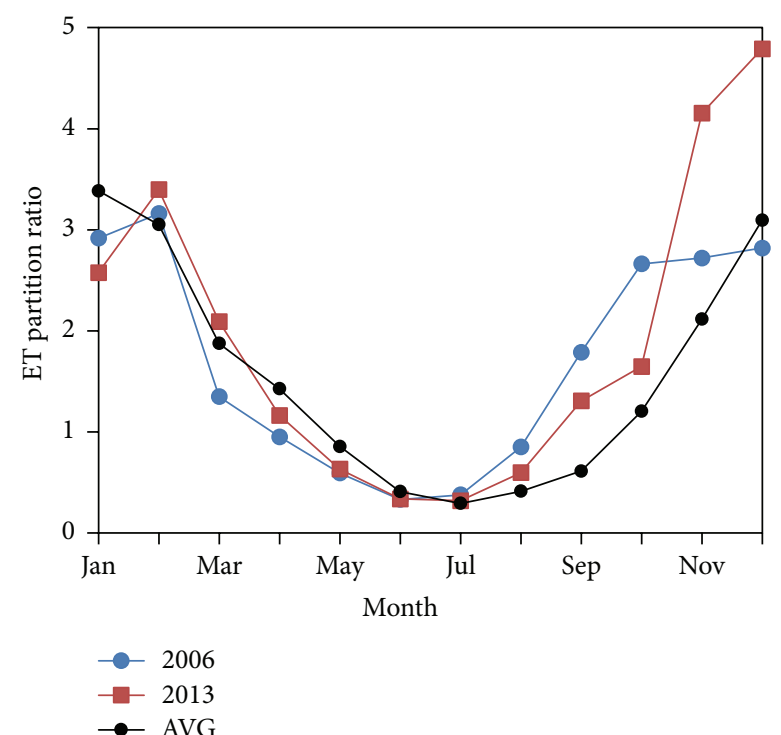

(b)

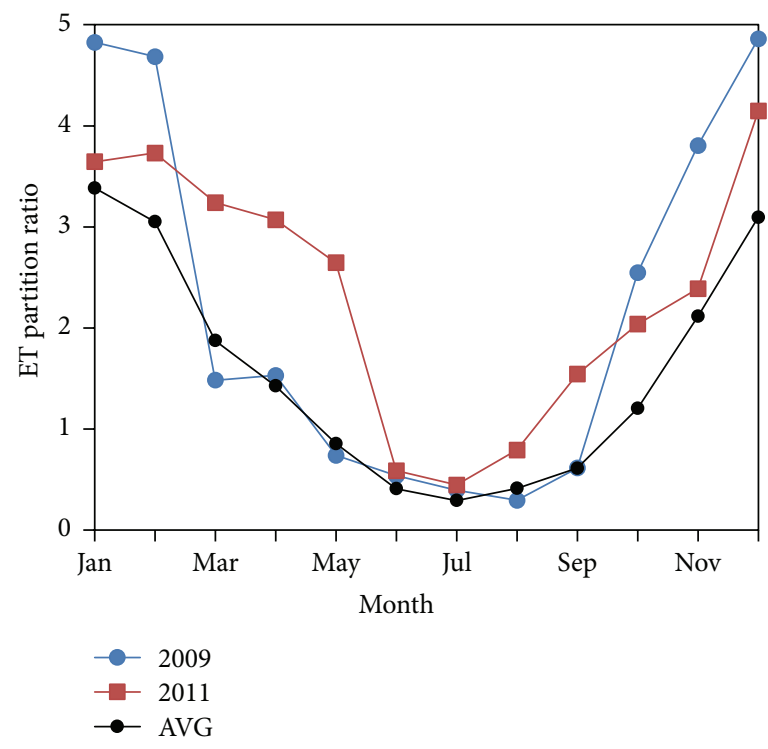

(c)

Figure 6: Monthly variations in the ET partition ratio during typical drought years. (a) Dry and rising; (b) flood and retreating; and (c) dry and retreating.

2013, which increased the exposed land area and exposure time. In those years, the normalized difference vegetation indexes (NDVIs) during the retreating season (from September to December) were substantially higher than mean NDVI from 2000 to 2013 (Figure 9). Ye et al. [25] also indicated that a low water level during autumn improved vegetation growth over the wetland shore region. The high NDVI and biomass for vegetation increased vegetation transpiration $[4,5]$, which is the main reason for the higher land surface ET during the retreating seasons in drought years.

When the abnormally low water levels occurred during the dry and rising seasons in 2004, 2007, 2009, and 2011, the wetland shore exposure persisted for a few months from autumn to spring. The NDVI from January to May during those drought years was close to the multiyear average value (Figure 10(a)), whereas the ratio of the accumulated precipitation to ET from September to May was remarkably lower than mean ratio from 2000 to 2013 (Figure 10(b)). The ratios of the accumulated precipitation to ET before April during 2004, 2007, and 2009 were less than 1, which caused soil water loss. The soil moisture deficit in the wetland shore limited evaporation from the soil and vegetation sprouting and growth [3, 49]. Therefore, the lower land surface ET rates during the dry and rising seasons in drought years were mainly attributed to reduced evaporation from the soil surface. 


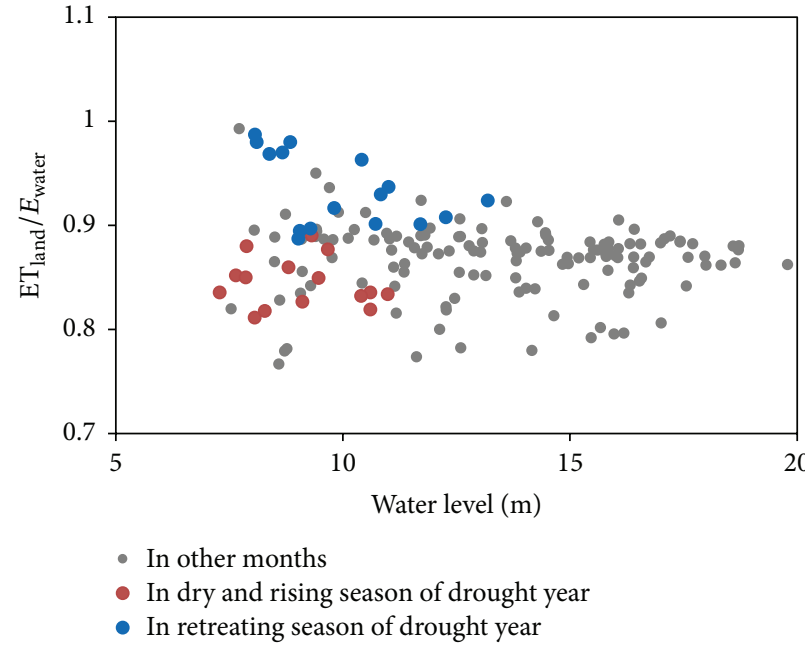

(a)

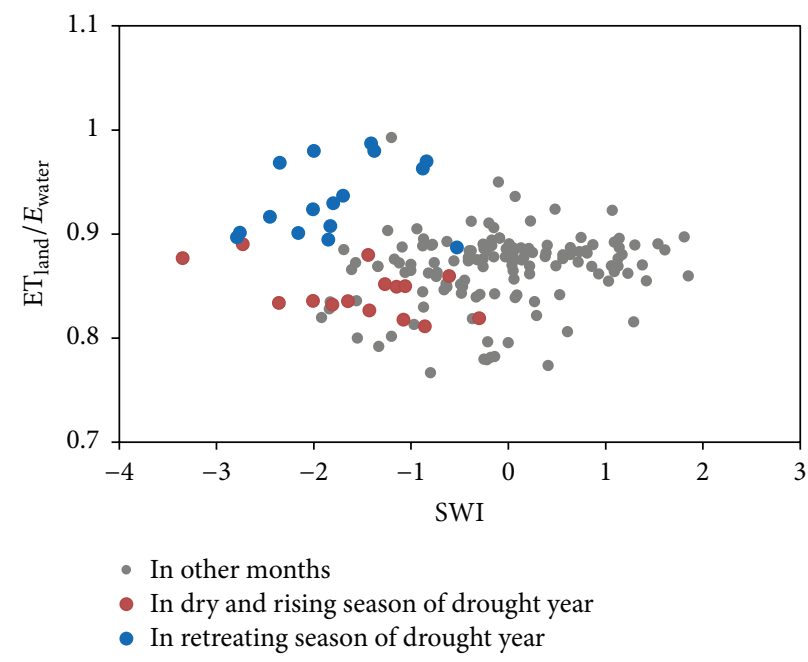

(b)

FIGURE 7: The relationship between the monthly $\mathrm{ET}_{\text {land }} / E_{\text {water }}$ and both (a) the water level and (b) the SWI.

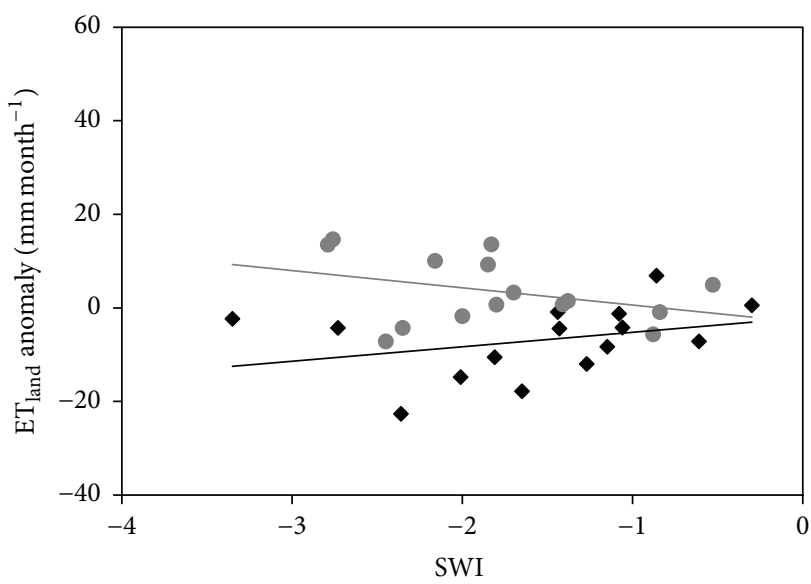

- ET in dry and rising season

- ET in retreating season

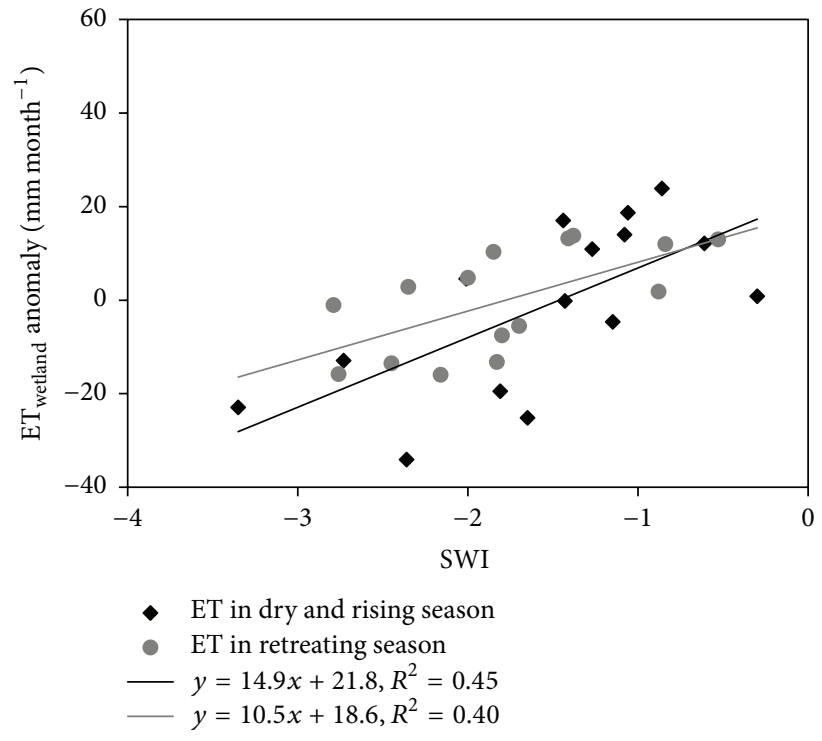

(b)

FIGURE 8: Response in (a) the land surface ET anomaly and (b) the wetland ET anomaly to the SWI during drought years.

\section{Conclusions}

Severely low water levels have occurred frequently over Poyang Lake wetland over the previous decade. In this study, wetland ET was separated into land ET and water evaporation in Poyang Lake wetland. The land ET was estimated by using the $T_{s}$-VI triangle method with MODIS data, and water evaporation was estimated with the Priestley-Taylor method by using meteorological data. The water evaporation rate $\left(E_{\text {water }}\right)$ was 1.01-1.30 times larger than the land ET rate $\left(\mathrm{ET}_{\mathrm{land}}\right)$. When considering the inundated area in Poyang Lake wetland, the ET partition ratio was larger than 1 when the water level was below $12.8 \mathrm{~m}$, and the water area percentage was less than $46 \%$. The monthly wetland ET decreased as the negative standardized water level index (SWI) decreased. However, the $\mathrm{ET}_{\text {land }}$ was higher than the average under abnormally low water levels during the retreating season, and the opposite results occurred during the dry and rising seasons.

The abnormally low water level decreased the wetland ET over Poyang Lake wetland; however, this relationship does not suggest more water resources in wetland shore. The low water level, in terms of the reduced inundation area and increased exposure of the land surface, increased the ET partition ratio, which indicates that more water loss came from the wetland shore, decreasing the available water in the soil of the exposed land. 


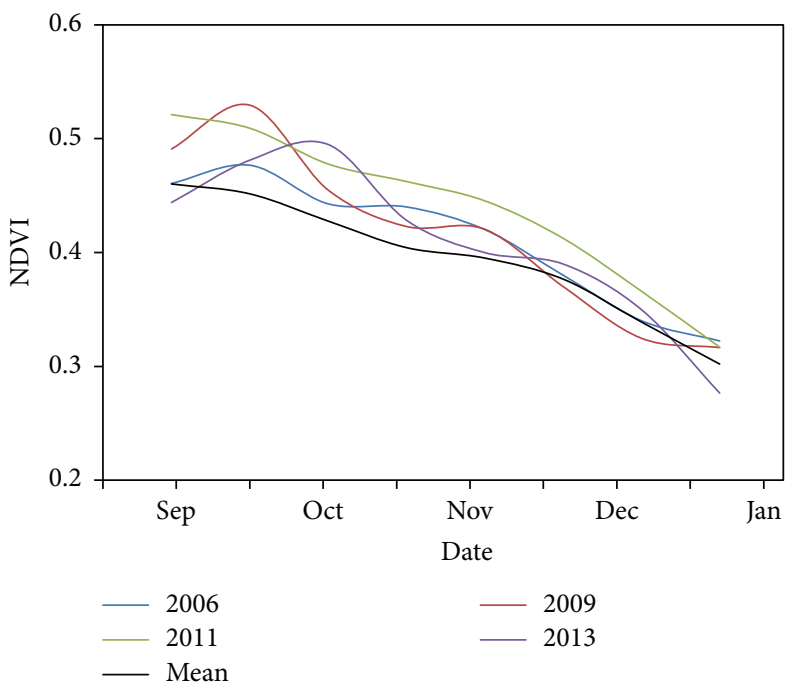

FIGURE 9: Variation in the NDVI from September to December during the drought years of 2006, 2009, 2011 , and 2013.

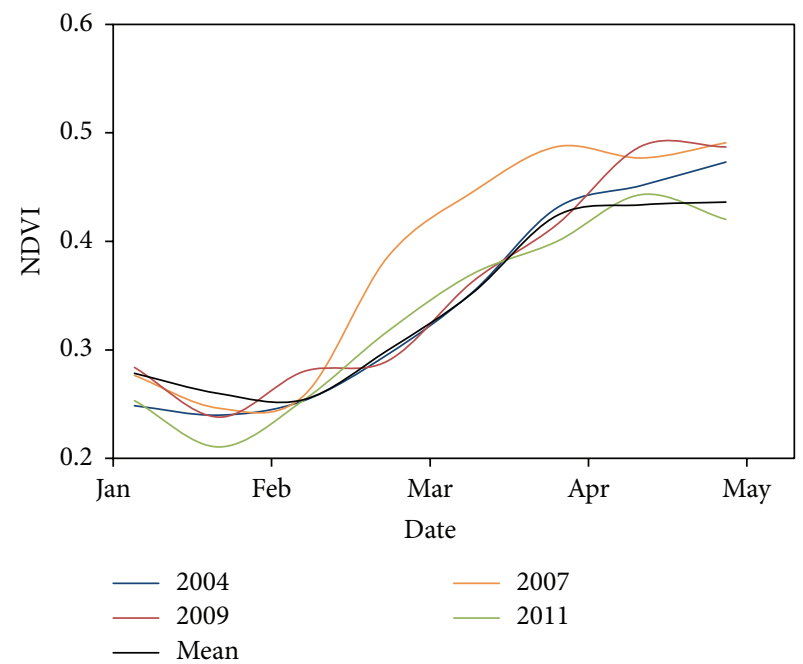

(a)

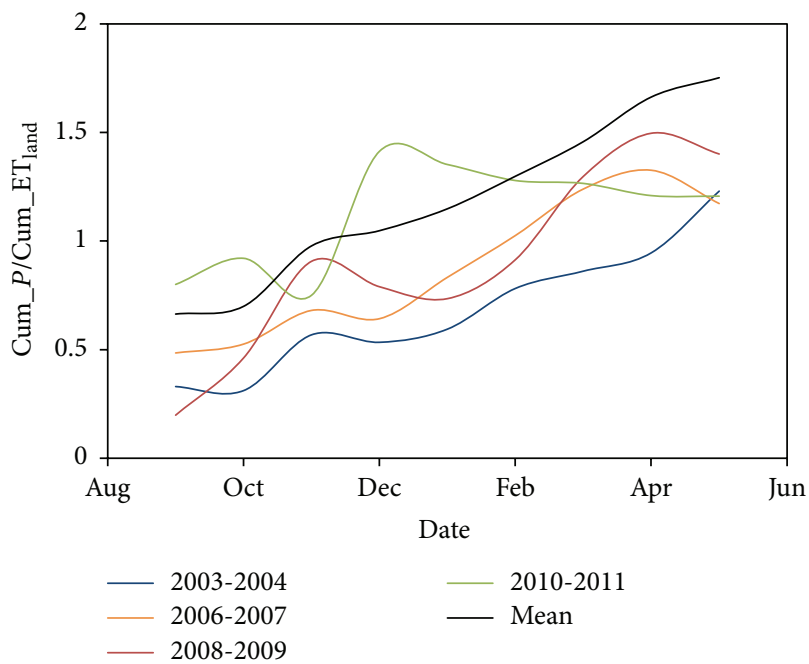

(b)

FIGURE 10: Variation in (a) the NDVI from January to May and (b) the ratio of the accumulated precipitation and ET from September to May during the drought years of 2004, 2007, 2009, and 2011.

\section{Nomenclature}

\section{Abbreviations and Symbols}

A: $\quad$ Water surface area proportion (\%)

$C_{E_{-} \text {water }}$ : Water surface evaporation component, $E_{\text {water }} \cdot A$

$C_{\text {ET_land }}: \quad$ Land surface ET component, $\mathrm{ET}_{\text {land }} \cdot(1-A)$

CV: $\quad$ Coefficient of variation

E: $\quad$ Evaporation (mm/time/area)

$e_{a}: \quad$ Actual vapor pressure $(\mathrm{kPa})$

$e_{s}: \quad$ Saturation vapor pressure $(\mathrm{kPa})$

ET: $\quad$ Evapotranspiration ( $\mathrm{mm} /$ time/area)

ET anomaly: Difference of ET to mean ET ( $\mathrm{mm} /$ time/area)
ET partition ratio: Ratio of $C_{\mathrm{ET} \text { _land }}$ to $C_{E_{-} \text {water }}$, $\mathrm{ET}_{\text {land }} \cdot(1-A) /\left(E_{\text {water }} \cdot A\right)$

$\mathrm{ET}_{\text {land }}$ : $\quad$ ET from the land surface ( $\mathrm{mm} /$ time/area)

$\mathrm{ET}_{\text {wetland }}: \quad$ Wetland ET ( $\mathrm{mm} /$ time/area $)$

$E_{\text {water }}$ : $\quad$ Evaporation from the water surface (mm/time/area)

G:

Green:

NDVI:

NDWI:

NIR:

$R_{n}$ :

$\mathrm{SD}$ :
Soil heat flux $\left(\mathrm{W} \mathrm{m}^{-2}\right)$

Reflectance in the green band Normalized difference vegetation index Normalized difference water index Reflectance in the NIR band Net radiation $\left(\mathrm{W} \mathrm{m}^{-2}\right)$ Standard deviation 
SWI: Standardized water level index

$T_{a}: \quad$ Air temperature (K)

$T_{\max }:$ Highest temperature at a given NDVI $(\mathrm{K})$

$T_{\min }:$ Lowest temperature in the full vegetation $\operatorname{cover}(\mathrm{K})$

$T_{s}: \quad$ Land surface temperature $(\mathrm{K})$

$U: \quad$ Wind velocity at a height of $2 \mathrm{~m}^{\left(\mathrm{m} \mathrm{s}^{-1}\right)}$

VI: Vegetation index

VPD: Saturation vapor pressure deficit $(\mathrm{kPa})$

$W: \quad$ Water level (m)

$W_{i j}$ : Normalized monthly water level of year $i$ and month $j(\mathrm{~m})$

$\overline{W_{j}}: \quad$ Multiyear mean of monthly mean water level for month $j(\mathrm{~m})$

$\gamma: \quad$ Psychrometric constant $\left(\mathrm{kPa} \mathrm{K}^{-1}\right)$

$\Delta: \quad$ Slope of the vapor pressure curve $\left(\mathrm{kPa} \mathrm{K}^{-1}\right)$

$\sigma_{j}:$ Standard deviation of monthly water level for month j

$\Phi: \quad$ Priestley-Taylor coefficient

$\Phi_{\max }$ : Priestly-Taylor coefficient of 1.26.

\section{Competing Interests}

The authors declare that they have no competing interests.

\section{Acknowledgments}

This work was jointly supported by the 973 Project (2012CB417003) and the National Natural Science Foundation of China (no. 41430855 and no. 41471022).

\section{References}

[1] M. C. Thoms, "Floodplain-river ecosystems: lateral connections and the implications of human interference," Geomorphology, vol. 56, no. 3-4, pp. 335-349, 2003.

[2] K. Tockner and J. A. Stanford, "Riverine flood plains: present state and future trends," Environmental Conservation, vol. 29, no. 3, pp. 308-330, 2002.

[3] M. S. Moran, R. L. Scott, T. O. Keefer et al., "Partitioning evapotranspiration in semiarid grassland and shrubland ecosystems using time series of soil surface temperature," Agricultural and Forest Meteorology, vol. 149, no. 1, pp. 59-72, 2009.

[4] P. A. M. Bachand, S. Bachand, J. Fleck, F. Anderson, and L. Windham-Myers, "Differentiating transpiration from evaporation in seasonal agricultural wetlands and the link to advective fluxes in the root zone," Science of the Total Environment, vol. 484, no. 1, pp. 232-248, 2014.

[5] E. G. Booth and S. P. Loheide, "Effects of evapotranspiration partitioning, plant water stress response and topsoil removal on the soil moisture regime of a floodplain wetland: implications for restoration," Hydrological Processes, vol. 24, no. 20, pp. 29342946, 2010.

[6] D. M. Lawrence, P. E. Thornton, K. W. Oleson, and G. B. Bonan, "The partitioning of evapotranspiration into transpiration, soil evaporation, and canopy evaporation in a GCM: impacts on land-atmosphere interaction," Journal of Hydrometeorology, vol. 8, no. 4, pp. 862-880, 2007.

[7] S. Sánchez-Carrillo, D. G. Angeler, R. Sánchez-Andrés, M. Alvarez-Cobelas, and J. Garatuza-Payán, "Evapotranspiration in semi-arid wetlands: relationships between inundation and the macrophyte-cover: open-water ratio," Advances in Water Resources, vol. 27, no. 6, pp. 643-655, 2004.

[8] S. Xu, T. Ma, and H. Wang, "Partitioning of vertical water loss in reed swamp wetlands: theory, research and application," Science China Technological Sciences, vol. 54, no. 11, pp. 2896-2903, 2011.

[9] M. Alvarez-Cobelas, S. Cirujano, and S. Sánchez-Carrillo, "Hydrological and botanical man-made changes in the Spanish wetland of las tablas de daimiel," Biological Conservation, vol. 97, no. 1, pp. 89-98, 2001.

[10] A. Van der Valk, C. Squires, and C. Welling, "Assessing the impacts of an increase in water level on wetland vegetation," Ecological Applications, vol. 4, no. 3, pp. 525-534, 1994.

[11] J.-S. Tsai, L. S. Venne, S. T. McMurry, and L. M. Smith, "Influences of land use and wetland characteristics on water loss rates and hydroperiods of playas in the Southern High Plains, USA," Wetlands, vol. 27, no. 3, pp. 683-692, 2007.

[12] T. E. Huxman, B. P. Wilcox, D. D. Breshears et al., "Ecohydrological implications of woody plant encroachment," Ecology, vol. 86, no. 2, pp. 308-319, 2005.

[13] Y. Liu, G. Wu, and X. Zhao, "Recent declines in China's largest freshwater lake: trend or regime shift?" Environmental Research Letters, vol. 8, no. 1, Article ID 014010, 2013.

[14] Q. Zhang, L. Li, Y.-G. Wang et al., "Has the three-gorges dam made the poyang lake wetlands wetter and drier?" Geophysical Research Letters, vol. 39, no. 20, 2012.

[15] L. Feng, C. Hu, X. Chen, X. Cai, L. Tian, and W. Gan, "Assessment of inundation changes of Poyang Lake using MODIS observations between 2000 and 2010," Remote Sensing of Environment, vol. 121, pp. 80-92, 2012.

[16] L. Feng, C. Hu, X. Chen, and X. Zhao, "Dramatic inundation changes of China's two largest freshwater lakes linked to the Three Gorges Dam," Environmental Science \& Technology, vol. 47, no. 17, pp. 9628-9634, 2013.

[17] B. Zhang, Research of Poyang Lake, Shanghai Scientific \& Technical Publishers, Shanghai, China, 1988.

[18] L. Cao and A. D. Fox, "Birds and people both depend on China's wetlands," Nature, vol. 460, no. 7252, p. 173, 2009.

[19] Y. Dong, "Background information of poyang lake and yangtze finless porpoises," in Contingent Valuation of Yangtze Finless Porpoises in Poyang Lake, China, pp. 5-36, Springer, 2013.

[20] L. I. Jiao, "Scientists line up against dam that would alter protected wetlands," Science, vol. 326, no. 5952, pp. 508-509, 2009.

[21] Q. Min and L. Zhan, "Characteristics of low-water changes in lake poyang during 1952-2011," Journal of Lake Sciences, vol. 24, pp. 675-678, 2012.

[22] Y. Jia, S. Jiao, Y. Zhang, Y. Zhou, G. Lei, and G. Liu, "Diet shift and its impact on foraging behavior of siberian crane (Grus Leucogeranus) in Poyang Lake," PLoS ONE, vol. 8, no. 6, Article ID e65843, 2013.

[23] X. Lai, D. Shankman, C. Huber, H. Yesou, Q. Huang, and J. Jiang, "Sand mining and increasing poyang lake's discharge ability: a reassessment of causes for lake decline in China," Journal of Hydrology, vol. 519, pp. 1698-1706, 2014.

[24] Q. Zhang, X.-C. Ye, A. D. Werner et al., "An investigation of enhanced recessions in poyang lake: comparison of yangtze river and local catchment impacts," Journal of Hydrology, vol. 517, pp. 425-434, 2014.

[25] C. Ye, Y. Liu, X. Zhao, and G. Wu, "Analysis of poyang lake wetland vegetation growth dynamics and its response to lake 
water level based on modis," Resources and Environment in the Yangtze Basin, vol. 22, pp. 705-712, 2013.

[26] L. Zhang, J. Yin, Y. Jiang, and H. Wang, "Relationship between the hydrological conditions and the distribution of vegetation communities within the Poyang Lake National Nature Reserve, China," Ecological Informatics, vol. 11, pp. 65-75, 2012.

[27] X. Zhao and Y. Liu, "Lake fluctuation effectively regulates wetland evapotranspiration: a case study of the largest freshwater lake in China," Water, vol. 6, no. 8, pp. 2482-2500, 2014.

[28] L. Yu, L. He, Q. Zhang, Y. Chen, and X. Wang, "Effects of the three gorges project on the typical wetland vegetations of poyang lake," Geographical Research, vol. 30, pp. 134-144, 2011.

[29] D. Shankman and Q. Liang, "Landscape changes and increasing flood frequency in China's Poyang Lake region," Professional Geographer, vol. 55, no. 4, pp. 434-445, 2003.

[30] L. Jiang and S. Islam, "A methodology for estimation of surface evapotranspiration over large areas using remote sensing observations," Geophysical Research Letters, vol. 26, no. 17, pp. 27732776, 1999.

[31] R. Tang, Z.-L. Li, and B. Tang, "An application of the Ts-VI triangle method with enhanced edges determination for evapotranspiration estimation from MODIS data in arid and semiarid regions: implementation and validation," Remote Sensing of Environment, vol. 114, no. 3, pp. 540-551, 2010.

[32] L. Jiang and S. Islam, "Estimation of surface evaporation map over southern great plains using remote sensing data," Water Resources Research, vol. 37, no. 2, pp. 329-340, 2001.

[33] W. E. Eichinger, M. B. Parlange, and H. Stricker, "On the concept of equilibrium evaporation and the value of the priestley-taylor coefficient," Water Resources Research, vol. 32, no. 1, pp. 161-164, 1996.

[34] G. Bisht, V. Venturini, S. Islam, and L. Jiang, "Estimation of the net radiation using modis (moderate resolution imaging spectroradiometer) data for clear sky days," Remote Sensing of Environment, vol. 97, no. 1, pp. 52-67, 2005.

[35] F. Caparrini, F. Castelli, and D. Entekhabi, "Estimation of surface turbulent fluxes through assimilation of radiometric surface temperature sequences," Journal of Hydrometeorology, vol. 5, no. 1, pp. 145-159, 2004.

[36] Q. Mu, M. Zhao, and S. W. Running, "Improvements to a MODIS global terrestrial evapotranspiration algorithm," Remote Sensing of Environment, vol. 115, no. 8, pp. 1781-1800, 2011.

[37] J.-P. Lhomme, "A theoretical basis for the Priestley-Taylor coefficient," Boundary-Layer Meteorology, vol. 82, no. 2, pp. 179191, 1997.

[38] R. B. Stewart and W. R. Rouse, "Substantiation of the priestley and taylor parameter $\alpha=1.26$ for potential evaporation in high latitudes," Journal of Applied Meteorology, vol. 16, pp. 649-650, 1977.

[39] K. Zhang, J. S. Kimball, R. R. Nemani, and S. W. Running, "A continuous satellite-derived global record of land surface evapotranspiration from 1983 to 2006," Water Resources Research, vol. 46, no. 9, Article ID W09522, 2010.

[40] P. D. Blanken, C. Spence, N. Hedstrom, and J. D. Lenters, "Evaporation from Lake Superior: 1. Physical controls and processes," Journal of Great Lakes Research, vol. 37, no. 4, pp. 707-716, 2011.
[41] J. D. Lenters, G. J. Cutrell, E. Istanbulluoglu et al., "Seasonal energy and water balance of a Phragmites australisdominated wetland in the Republican River basin of southcentral Nebraska (USA)," Journal of Hydrology, vol. 408, no. 1-2, pp. 19-34, 2011.

[42] J. Tanny, S. Cohen, S. Assouline et al., "Evaporation from a small water reservoir: direct measurements and estimates," Journal of Hydrology, vol. 351, no. 1-2, pp. 218-229, 2008.

[43] W. Brutsaert, Evaporation into the Atmosphere: Theory, History, and Applications, Reidel, Dordrecht, The Netherlands, 1982.

[44] S. K. Mcfeeters, "The use of the Normalized Difference Water Index (NDWI) in the delineation of open water features," International Journal of Remote Sensing, vol. 17, no. 7, pp. 14251432, 1996.

[45] Y. Liu, P. Song, J. Peng, and C. Ye, "A physical explanation of the variation in threshold for delineating terrestrial water surfaces from multi-temporal images: effects of radiometric correction," International Journal of Remote Sensing, vol. 33, no. 18, pp. 5862$5875,2012$.

[46] G. Wu and Y. Liu, "Capturing variations in inundation with satellite remote sensing in a morphologically complex, large lake," Journal of Hydrology, vol. 523, pp. 14-23, 2015.

[47] T. B. McKee, N. J. Doesken, and J. Kleist, "The relationship of drought frequency and duration to time scales," in Proceedings of the 8th Conference on Applied Climatology, pp. 179183, American Meteorological Society, Anaheim, Calif, USA, January 1993.

[48] X. Dai, R. Wan, G. Yang, and W. Xiaolong, “Temporal variation of hydrological rhythm in poyang lake and the associated water exchange with the changjiang river," Scientia Geographica Sinica, vol. 34, pp. 1488-1496, 2014.

[49] J. M. Jacobs, S. L. Mergelsberg, A. F. Lopera, and D. A. Myers, "Evapotranspiration from a wet prairie wetland under drought conditions: Paynes prairie preserve, Florida, USA," Wetlands, vol. 22, no. 2, pp. 374-385, 2002. 

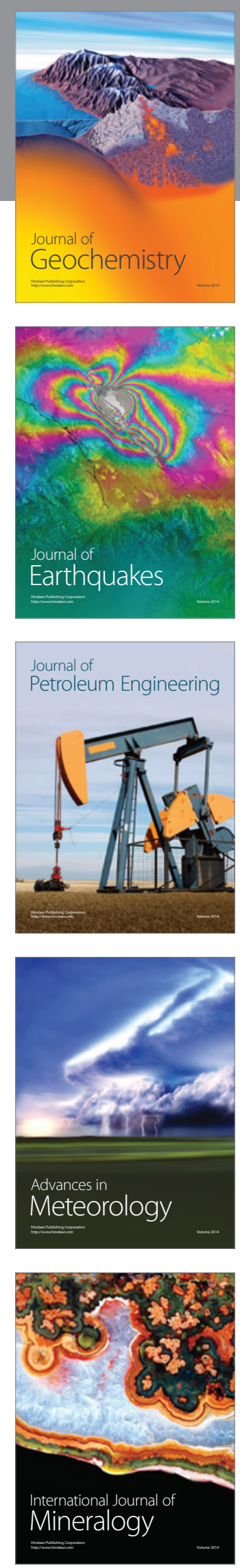
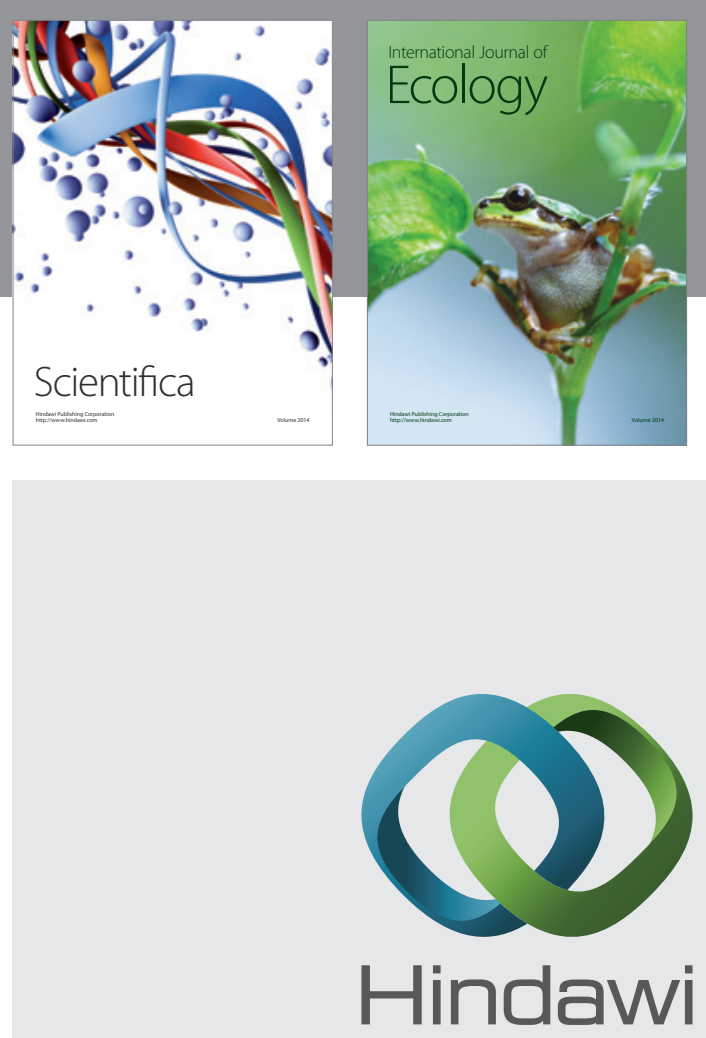

Submit your manuscripts at

http://www.hindawi.com
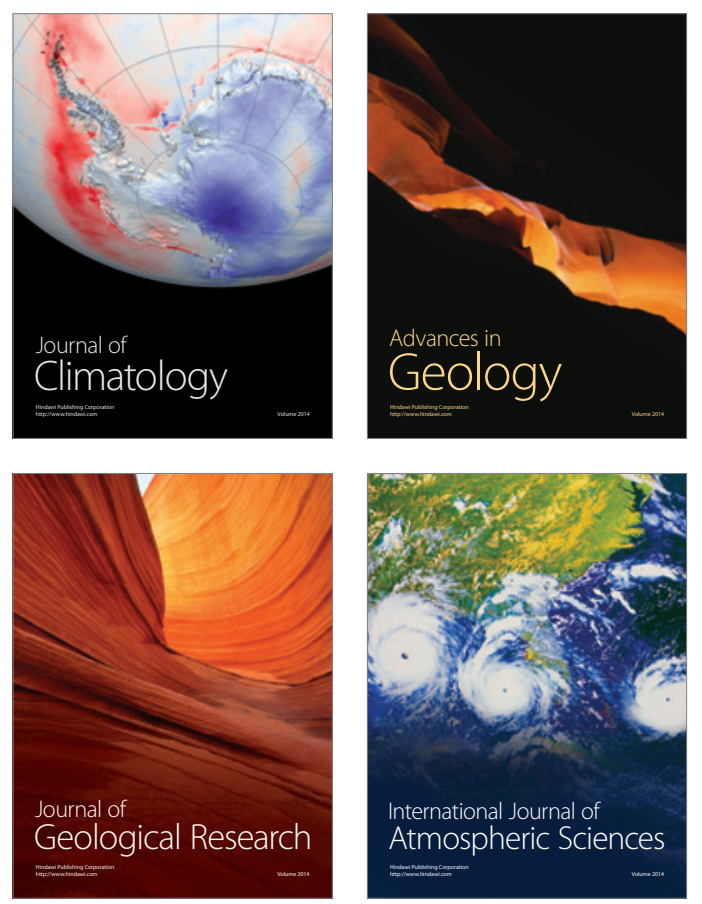

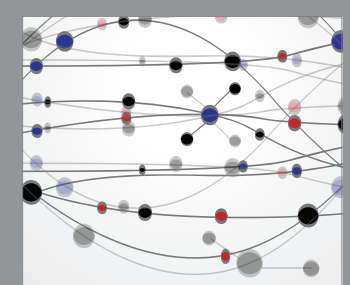

The Scientific

\section{World Journal}
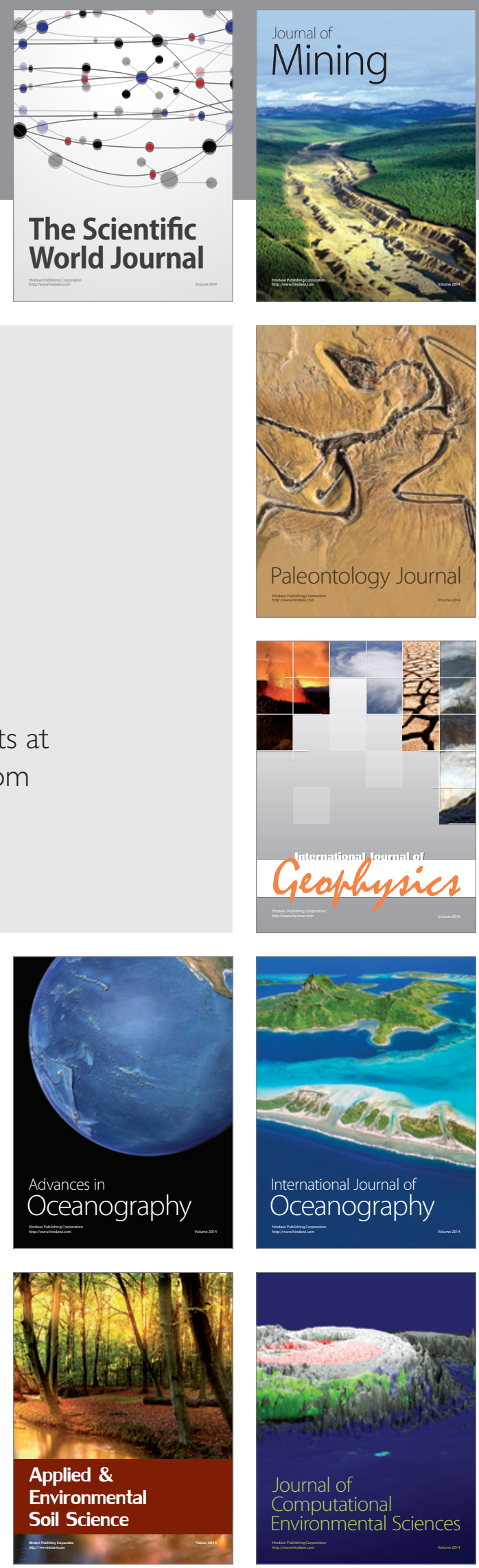